\title{
Health Status of School Going Children: A Cross sectional study in urban area of Jhalawar District, Rajasthan
}

Manish Jain ${ }^{1}$, Mayank Jain ${ }^{2}$, Vinod Kumar ${ }^{2}$, Kapil Garg $^{3}$, Asif A Qureshi ${ }^{3}$, Ravi Khichar ${ }^{4}$

${ }^{1}$ Assistant Professor, ${ }^{2}$ Associate Professor, ${ }^{3}$ Senior Demonstrator, ${ }^{4}$ PG Resident, Department of Community Medicine, Jhalawar Medical College, Jhalawar, Rajasthan.

Correspondence : Dr Mayank Jain, Email: doc.jain16@gmail.com

\section{Abstract:}

Introduction: The school going age is a formative period, both physically as well as mentally. Poor health status in school aged children is among the causes of poor class performance and high absenteeism. Objectives: To assess the health and nutritional status of the school going children in urban area and to determine the association of health problems with age and gender. Method: A cross sectional study was carried out in government schools of urban field practice area of tertiary care institute, Jhalawar, Rajasthan. Study was carried out among 2193 students in four government schools. A pretested, semi structured questionnaire was used for collection of data on socio-demographic characters and their health profile. A detailed clinical examination was done from head to toe for every child. Weight and height were measured. Data was entered into the Microsoft Excel 10. Chi square test of significance was used for statistical analysis. Results: Most common health problem was dental caries (15.0\%) followed by refractive errors (13.1\%) and pallor (12.6\%). Proportions of pallor and refractive error were significantly increased with increase in age of study participants. $16.8 \%$ of the students were found to be having thinness. Moderate stunting was present in 7.3\% students. Conclusion: Dental caries, refractive errors and pallor were the common morbidities. A significant proportion of school children were undernourished.

Key words: Dental caries, Health status, Morbidities, School children

\section{Introduction:}

The health of school children and youth is of fundamental importance. Since the beginning of $20^{\text {th }}$ century, the importance of school health has been acknowledged across countries. The school health committee (1961) in India recommended medical examination of children at the time of school entry and thereafter every 4 years. ${ }^{[1]}$

Health of the children is the country's biggest human investment. The quality of life of school children, by all standards continues to be poor. It is estimated that every third child has some sign if ill health manifesting in the form of dental, visual and hearing problems, nutritional deficiencies, respiratory infections, skin disorders, loco-motor disabilities etc. $^{[2]}$

In developing countries, the increased burden of communicable diseases among school going children due to poor practices of personal hygiene and insufficient sanitary conditions remains anissue of public health concern. ${ }^{[3]}$ Early detection of childhood diseases through school health check-ups at periodic intervals can help in preventing complications.

\begin{tabular}{|c|l|}
\hline Quick Response Code & Access this article online \\
\hline $\mathbf{D}$ & Website : \\
& www.healthlinejournal.org \\
\cline { 2 - 2 } & DOI : \\
\hline
\end{tabular}

\section{How to cite this article :}

Jain M, Jain M, Kumar V, Garg K, Qureshi A, Khichar R. Health Status of School going Children:A Cross sectional study in urban area of Jhalawar District, Rajasthan. Healthline. 2021; 12(1):15-21. 
Research indicates that poor health status in school aged children is among the causes of low school enrollment, poor class performance, high absenteeism, and early drop-out from schools. These can be easily prevented by promotion of personal hygiene, nutritionand early identificationand treatment of the childhood illnesses. ${ }^{[4]}$

The school going age is a formative period, both physically as well as mentally, transforming the children into promising adults. Pattern of morbidities amongst school aged children vary from one place to another.Poor health status in school age can interfere with learning process and will affect cognitive functions as well as work capacity. With this background, this study was conducted to assess the health status of the school going children in urban schools of Jhalawar district of Rajasthan.

\section{Method:}

Study Design: The present study was a school based descriptive cross sectional study.

Study area: Study was carried out in government schools of urban field practice area of atertiary care institute in Jhalawar. Jhalawar is a district of Rajasthan, located in southeastern location of state.

Study period: Study was conducted from June 2019 to February 2020.

Study population: Study was carried out among students from class $1^{\text {st }}$ to $12^{\text {th }}$ standard in government schools. There are total 14 government schools in urban field practice area of tertiary care institute, Jhalawar. Among these, 04 government schools were selected randomly for the present study. Of these selected schools, two schools were of upper primary standard, one was secondary and one school was of senior secondary level. Total 2381 students were registered in these four schools.

Inclusion criteria: All students present on the days of assessments from class $1^{\text {st }}$ to $12^{\text {th }}$ standard

Exclusion criteria: Students absent during all visits to schools for assessment.

Sample size: Out of total 2381 registered students, 188 students were absent during all visits to schools, hence could not be assessed. So in presence study, total 2193 students were included as study participants.

Method of data collection:

After taking appointments, four to five visits were done to each school on successive days for assessment of students. Assessment was done throughout the school hours. A pretested, predesigned and semi structured questionnaire was used for collection of data on socio-demographic characters ie., age, sex, residenceand their health profile. Age of the students was taken as per school records. A detailed clinical examination was done from head to toe for every child and clinical history was also taken. Visual acuity was tested by using Snellen's charts. Height in centimeters was marked on a wall with the help of a measuring tape. All students were measured against the wall without foot wear and with heels together and their heads positioned so that the line of vision was perpendicular to the body. A glass scale was brought down to the topmost point on the head. The height was recorded to the nearest $1 \mathrm{~cm}$. Weight was recorded after removing belts and shoes using digital weighing machine with accuracy of up-to 100 grams. Body Mass Index (BMI) of all the students was calculated by using the formula: BMI=Weight (in kg)/ (Height in meters) ${ }^{2}$. The height and BMI of the students was then compared with the WHO standards ${ }^{[5]}$ Laboratory investigations were not done due to practical difficulties. Minor ailments of the students were managed at the same time. Students requiring further investigation or management were instructed to consult outpatient departments of tertiary care institute. Health education was provided to students by health talk in prayer assembly using audio visual aids.

Data entry and analysis:

Data was coded and entered into the Microsoft Excel 10. Appropriate tables and figures were generated. Chi square test of significance was used for statistical analysis of the health profile in the school children. $\mathrm{p}$ value of less than 0.05 was considered significant. 
Healthline Journal Volume 12 Issue 1 (January-March 2021)

Ethical Approval: Before commencing the study, approval from institutional ethical committee was taken. The purpose of the study was explained in detail and permissions were taken from the principals of the schools. Parents of each participant were informed about the study protocol and informed consent was obtained.

\section{Results:}

In present study, out of total 2193 students, $52.8 \%$ students were from standard I to $\mathrm{V}$ while $31.0 \%$ students belonged to standard VI to VIII. 16.1\% students were studying in standard IX to XI. Out of total 2193 study participants, 1257 (57.3\%) were males and $936(42.7 \%)$ were females. Majorities of students were from age group 9 to 12 years (42.5\%) followed by age group 5 to 8 years $(34.7 \%)$. Four hundred ninety eight $(22.7 \%)$ students were in age 13 years and above (Table 1).

Table 1 : Demographic profile of study subjects $(n=2193)$

\begin{tabular}{|c|c|c|c|}
\hline Characteristic & Variable & Number & Percentage \\
\hline \multirow{4}{*}{$\begin{array}{c}\text { Age Groups } \\
\text { (years) }\end{array}$} & $5-8$ & 762 & $34.7 \%$ \\
\cline { 2 - 4 } & $13-16$ & 444 & $20.2 \%$ \\
\cline { 2 - 4 } & 17 and above & 54 & $2.5 \%$ \\
\hline \multirow{3}{*}{ Gender } & Male & 1257 & $57.3 \%$ \\
\cline { 2 - 4 } & Female & 936 & $42.7 \%$ \\
\hline \multirow{3}{*}{ Education } & I- V & 1158 & $52.8 \%$ \\
\cline { 2 - 4 } & VI-VIII & 681 & $31.0 \%$ \\
\cline { 2 - 4 } & IX-XI & 354 & $16.1 \%$ \\
\hline
\end{tabular}

Most common health problem among school children was dental caries (15.0\%) followed by refractive errors (13.1\%) and pallor (12.6\%). Upper respiratory infections were present in $5.1 \%$ students while $4.1 \%$ students were suffering from ear discharge. Conjunctivitis was present in $1.2 \%$ students. $2.1 \%$ were suffering from Skin diseases. Other health problems such as Impacted wax in ears, Colour Blindness, Bitots Spots, Angular Stomatitis, Spongy
Table 2: Health problems of school children $(n=2193)$

\begin{tabular}{|c|c|c|}
\hline Health problems* $^{*}$ & Number & Percentage \\
\hline Dental Caries & 330 & 15.0 \\
\hline Ear discharge & 90 & 4.1 \\
\hline Pallor & 276 & 12.6 \\
\hline Refractive errors & 288 & 13.1 \\
\hline Conjunctivitis & 27 & 1.2 \\
\hline Worm infestations & 30 & 1.4 \\
\hline Upper respiratory infections & 111 & 5.1 \\
\hline Skin diseases & 45 & 2.1 \\
\hline Others & 108 & 4.9 \\
\hline
\end{tabular}

* Multiple responses

Bleeding Gums, Asthma, Hypertension, Sports injuries, Menstrual irregularities in girls etc. were found in $4.9 \%$ of children. (Table 2 )

Table 3 is depicting association between health problems and age of the school children. Proportions of pallor and refractive error were increased with increase in age of study participants and association were statistically significant $(\mathrm{p}<0.05)$. None of the other health problems were significantly associated with age of the school children ( $p>0.05)$.

Association between health problems and gender of school children is illustrated in Table 4. Proportion of pallor was significantly higher $(\mathrm{p}<0.05)$ among female students (15.7\%) as compared to male students (10.3\%). No significant association found between other health problems and gender of school children $(p>0.05)$.

Figure 1 represents nutritional status of School Children according to BMI for age $\mathrm{Z}$ score charts. BMI for age was normal in 1712 (78.1\%) students. Overall $370(16.8 \%)$ of the students were found to be having thinness and severe thinness was present in 63 (2.9\%) children. However, 48 (2.2\%) students were found to be overweight.

Nutritional status of students according to Height for age Z score charts is illustrated in Figure 2. Height for age was normal in 2016 (91.9\%) students. 
Table 3: Association between health problems and age of school children

\begin{tabular}{|c|c|c|c|c|c|}
\hline \multirow{2}{*}{ Health problems } & \multicolumn{3}{|c|}{ Age Groups (years) } & \multirow{2}{*}{$\begin{array}{c}\text { Total } \\
(n=2193)\end{array}$} & \multirow{2}{*}{ p value } \\
\hline & $5-8(n=762)$ & $9-12(n=933)$ & $\geq 13(n=498)$ & & \\
\hline Dental Caries & $144(18.9)$ & $132(14.1)$ & $54(10.8)$ & $330(15.0)$ & 0.07 \\
\hline Ear discharge & $45(5.9)$ & $36(3.9)$ & $9(1.8)$ & $90(4.1)$ & 0.19 \\
\hline Pallor & $63(8.3)$ & $117(12.5)$ & $96(19.3)$ & $276(12.6)$ & 0.004 \\
\hline Conjunctivitis & $12(1.6)$ & $12(1.3)$ & $3(0.6)$ & $27(1.2)$ & 0.90 \\
\hline Refractive errors & $42(5.5)$ & $147(15.8)$ & 99 (19.9) & $288(13.1)$ & $<0.001$ \\
\hline Worm infestations & $18(2.4)$ & $12(1.3)$ & $0(0.0)$ & $30(1.4)$ & 0.27 \\
\hline $\begin{array}{l}\text { Upper respiratory } \\
\text { infections }\end{array}$ & $48(6.3)$ & $36(3.9)$ & $27(5.4)$ & $111(5.1)$ & 0.53 \\
\hline Skin diseases & $27(3.5)$ & $12(1.3)$ & $6(1.2)$ & $45(2.1)$ & 0.23 \\
\hline Others & $33(4.3)$ & $45(4.8)$ & $30(6.0)$ & $108(4.9)$ & 0.85 \\
\hline
\end{tabular}

Figures in parentheses are indicating percentages

Table 4: Association between health problems and gender of school children

\begin{tabular}{|c|c|c|c|c|}
\hline \multirow{2}{*}{ Health problems } & \multicolumn{2}{|c|}{ Gender } & \multirow{2}{*}{$\begin{array}{c}\text { Total } \\
\text { (n= 2193) }\end{array}$} & p value \\
\cline { 2 - 3 } & Male (n=1257) & Female (n=936) & $330(15.0)$ & 0.29 \\
\hline Dental Caries & $174(13.8)$ & $156(16.7)$ & $90(4.1)$ & 0.50 \\
\hline Ear discharge & $57(4.5)$ & $33(3.5)$ & $276(12.6)$ & 0.03 \\
\hline Pallor & $129(10.3)$ & $147(15.7)$ & $27(1.2)$ & 0.81 \\
\hline Conjunctivitis & $18(1.4)$ & $9(1.0)$ & $288(13.1)$ & 0.51 \\
\hline Refractive errors & $174(13.8)$ & $114(12.2)$ & $30(1.4)$ & 0.86 \\
\hline Worm infestations & $18(1.4)$ & $12(1.3)$ & $111(5.1)$ & 0.34 \\
\hline $\begin{array}{c}\text { Upper respiratory } \\
\text { infections }\end{array}$ & $72(5.7)$ & $39(4.2)$ & $45(2.1)$ & 0.75 \\
\hline Skin diseases & $24(1.9)$ & $21(2.2)$ & $108(4.9)$ & 0.21 \\
\hline Others & $51(4.1)$ & $57(6.1)$ & & \\
\hline
\end{tabular}

Figures in parentheses are indicating percentages 
Figure 1: Distribution of School Children according to Nutritional status based on BMI for age

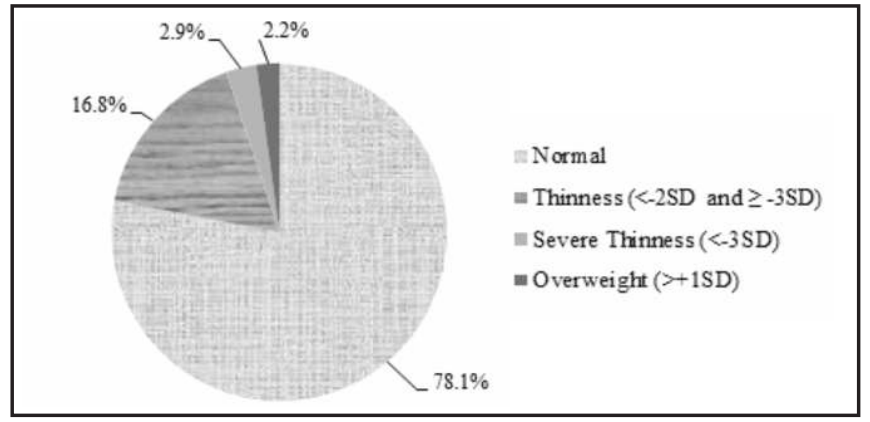

Figure 2: Distribution of School Children according to Nutritional status based on Height for age

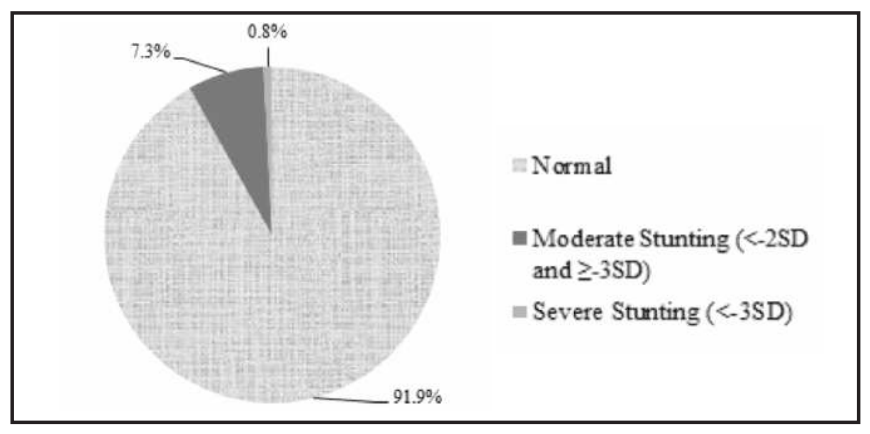

Moderate stunting was present in 160 (7.3\%) students. Severe stunting was found in $17(0.8 \%)$ students.

\section{Discussion:}

Present study was carried out to assess the health profile of school going children. School plays a crucial role in establishment of healthy behavior pattern among children as well as in improving the children's physical, social and mental development.

In this study, dental caries was present in $15.0 \%$ school children. This finding is in accordance to study by Abu Bashar Md et $\mathrm{al}^{[6]}$ in which dental caries was present in $18.3 \%$ school children. Dental caries was found in $24.2 \%$ students in study by Esimai OA et al. ${ }^{[7]}$ In contrast to our study, Pradeep Savale et $\mathrm{al}^{[8]}$ reporteddental caries in $62.36 \%$ school going children.

Refractive errors were present in $13.1 \%$ school going children in current study which is similar to study by Nehal Patel et al[9](10.2\%), Harpal Singh et $\mathrm{al}^{[10]}(13.09 \%)$ and Dambhare et $\mathrm{al}^{[11]}(13.8 \%)$. In the study by Thekdi et al, ${ }^{[12]}$ refractive errors were found in $37 \%$ of the school children. In contrast to our study, refractive errors werepresent in $2.7 \%$ in study by Ananthakrishnan et $\mathrm{al}^{[13]}$ and $36.62 \%$ in study by Deshpande Jayant D et al. ${ }^{[14]}$

In present study, pallor was present in $12.6 \%$ school going children. This finding was matched with the result of study by Mohan Shinde et al ${ }^{[15]}$ (15.69). In contrast to present study, the prevalence of anaemia in children was $42 \%$ in study by Nilesh Thakor et $\mathrm{al}^{[16]}$ and $38.23 \%$ in study by Syed Abid Asghar et al. ${ }^{[17]}$

In present study, problem of ear discharge was present in $4.1 \%$ school children. This finding is similar to study by Nehal Patel et $\mathrm{al}^{[9]}$ in which ear discharge was observed in $2.8 \%$ study participants. However, Syed AbidAsghar et al $^{[17]}$ reported ear discharge in $10.0 \%$ school children.

Upper respiratory infections were present in $5.1 \%$ study participants in present study while 1.2\% students were suffering from conjunctivitis. Mohan Shinde et $\mathrm{al}^{[15]}$ reported Upper respiratory infections in $3.77 \%$ while conjunctivitis in $0.44 \%$ students. Upper respiratory tract infections were present in $4.67 \%$ students in study by Vidya Rani et al. ${ }^{[18]}$ In contrast to our study, Upper respiratory infections were reported in $36.99 \%$ in study by Nehal Patel et $\mathrm{al}^{[9]}$ and $17.1 \%$ in study by Abu Bashar Md etal. ${ }^{[6]}$

In present study, proportion of pallor was significantly higher among female students (15.7\%) as compared to male students $(10.3 \%)$. In contrast to our study, association between gender of the study participants and anemia was not significant in study by Abu Bashar Md et al ${ }^{[6]}$ and Syed AbidAsghar et al. ${ }^{[17]}$

No significant association found between other health problems and gender of school children in our study. However, prevalence of dental caries was significantly higher among female children in study by Syed Abid Asghar et al. ${ }^{[17]}$

In present study, according to BMI for age cut off, $16.8 \%$ of the students were found to be having thinness. Severe thinness was present in 2.9\% children. In contrast to our study, Srivastav $S$ et $\mathrm{al}^{[19]}$ reported in their study thatprevalence of thinness was found to be $23.2 \%$ and severe thinness was found to be $7.4 \%$. In study done by Rupali R. 
Rajput et $\mathrm{al}^{[20]}, 35.4 \%$ had thinness based on $\mathrm{BMI}$, $25.29 \%$ had mild to moderate thinness and $10 \%$ had severe thinness. Findings of our study are also comparatively less as compared to the study findings of Anand et al ${ }^{[21]}$, in which prevalence was found to be $30.1 \%$ in girls and $43.8 \%$ in boys and study by Malhotra and Passi $^{[2]}$ which also reported the prevalence of thinness among adolescent girls as $30.6 \%$.

In our study, $2.2 \%$ students were found to be overweight. This finding is in accordance to study done by Srivastav S et al, ${ }^{[19]}$ only $2 \%$ were found to be overweight. $3.3 \%$ of the participants were found to be obese (BMI >2 SD) in study by Rupali R. Rajput et $\mathrm{al}^{[20]}$. Study done in south India on 1800 school children by Kumaravel $\mathrm{V}$ et $\mathrm{al}^{[23]}$, found prevalence rates of overweight, obesity, and thinness as per international standard were $15.3 \%, 8.1 \%$ and $2.6 \%$ respectively.

In present study, Height for age was normal in 91.9\% students. Moderate stunting was present in $7.3 \%$ students. Severe stunting was found in $0.8 \%$ students.In study by Rupali R. Rajput et $\mathrm{al}^{\left[{ }^{[20]}\right.}$ the prevalence of stunting was $10.4 \%$, including $0.1 \%$ of severely stunted children. The prevalence of stunting was found to be $12 \%$ in boys and $13.3 \%$ in girls whereas severe stunting was $0.7 \%$ in boys and $3.9 \%$ in girls study done by Srivastav $\mathrm{S}$ et al. ${ }^{[19]}$ Anand et al ${ }^{[21]}$ found the prevalence of stunting to be $37.2 \%$ in boys and $19.9 \%$ in girls.

\section{Conclusion:}

Study attempts to highlight the health profile and nutritional status of school going children. Dental caries, refractive errors and pallor were the common morbidities among school going children in present study. A significant proportion of school children were undernourished.

\section{Recommendation:}

Health education should be a regular part of teaching curriculum. Periodic school health checkups involving local health workers and school teachers should be done for early diagnosis and treatment to deal this problem. A comprehensive study with large sample size involving multiple schools including rural and tribal areas will provide better picture of the situation.

\section{Limitation of the study:}

The present study was carried out among students of urban government schools. The scenario may be different in students of private affluent schools. Health profile may be worsening in students of rural settings.

\section{Relevance of the study:}

An effort is made to assess the health profile and nutritional status of students in urban schools. Early detection of these childhood health problems and under nutrition through periodic school health check-ups can help in improving learning process and cognitive functions as most of the morbidities observed among the school going children can be prevented and the health of the children can be enriched by well-timed intervention.

\section{Acknowledgement :}

Authors would like to thank all the school principals and school teachers for cooperating in health assessment. Authors would also like to acknowledge all the interns and post-graduates in the department of community medicine for conducting in health assessment.

\section{Declaration:}

Funding: Nil

Conflict of Interest: Nil

\section{References:}

1. Park K. Park's Textbook of preventive and social medicine, 25th edition, Jabalpur, BanarsidasBhanot Publishers; 2019. p.633.

2. Naseem A, Rao NG. Comprehensive study of health problems in school children of Hyderabad, India. Int J ContempPediatr 2016;3:801-5.

3. Oyibo PG. Basic personal hygiene: Knowledge and Practices among school going children aged 6-14 years in Abraka, Delta state, Nigeria. Continental J Tropical Medicine 2012; 6 (1): 5-11.

4. Nigudgi SR, Reddy S, Kapate R. Morbidity pattern among school children of Gulberg city. MedicaInno-vatica. Dec 2012; 1(2): 1-3.

5. Development of a WHO growth reference for schoolaged children and adolescents. Bulletin of the World Health Organisation, volume 85, No 9, pp 649- 732, September 2007. Available at http://www.who.int/bulletin/volumes/85/9/07043497/en/print.html\#R18\#R18. 
6. Md AB, Aggarwal AK, Pilania M. A Study to Assess Pattern of Morbidities among Adolescents under School Health Program from Arural Block of North India. Nat J Community Medicine. 2017;8(12):721-5.

7. Esimai OA, Ojofeitimi E O. Nutrition and Health Status of Adolescents in a Private Secondary School in Port Harcourt. Health Science Journal. 2015;9(5):1-5.

8. Savale P, Lanjewar R. Epidemiological Study of Oral Hygiene and Prevalence of Dental Caries in Secondary School Going Children. Nat J Community Medicine 2019;10(3):155-8.

9. Patel N, Gunjana G, Patel S, Thanvi R, Sathvara P, Joshi R. Nutrition and health status of school children in urban area of Ahmedabad, India: Comparison with Indian Council of Medical Research and body mass index standards. J Nat ScBiol Med 2015;6:372-7.

10. Singh H, Saini VK, Yadav A, Soni B. Refractive errors in school going children -data from a school screening survey programme. Nat J Community Medicine 2013;4(1):137-40.

11. Dambhare DG, Bharambe MS, Mehendale AM, Garg BS. Nutritional Status and Morbidity among School going Adolescents in Wardha, a Peri-Urban area. Online J Health Allied Sci 2010;9:3.

12. Thekdi K, Kartha G, Nagar SS. Assessment of nutritional and health status of the school students of 5th to 9th standard (11 to 15 years age group) of Surendranagar district, Gujarat state, India. Healthline 2011; 2:59-61.

13. Ananthakrishnan S, Pani SP, Nalini P. A comprehensive study of morbidity in school age children. Indian Pediatr 2001; 38:100917.

14. Deshpande JD, Malathi K. Prevalence of ocular morbidities among school children in rural area of North Maharashtra in India. Nat J Community Medicine 2011;2(2):249-54.
15. Shinde M, Trivedi A, Joshi A. Morbidity pattern among school children of rural area of Obaidullaganj block of Raisen District of Madhya Pradesh. IntJ Adv Med 2015;2:144-6.

16. Thakor N, Shukla A, Bala DV, Vala M, Ninama R. Health status of children of primary and secondary boarding schools of Gandhinagar district. Int J Med Sci Public Health 2014;3:866-9.

17. Asghar SA, Gupta P, Srivastava MR, Srivastava JP, Zaidi ZH. Health status of primary school children: study from a rural health block of Lucknow. Int J Community Med Public Health 2017;4:2498-501.

18. Rani V, Srivastava DK, Jain PK, Kumar S, Singh NP, Dixit AM. Morbidity pattern among primary school children in a rural area of Uttar Pradesh. National J Community Medicine 2014;5(4):392-6.

19. Srivastav S, Mahajan H, Grover VL. Nutritional Status of the Government School Children of Adolescent Age Group in Urban Areas of District Gautambudhnagar, Uttar Pradesh. Natl J Community Med 2013; 4(1): 100-3.

20. Rajput RR, Mangulikar SK, Howal PV. Health profile of government aided private school children in urban slum of Solapur, Southern Maharashtra, India. Int J Res Med Sci 2016;4:2728-33.

21. K.Anand, S.Kant, S.K Kapoor. Nutritional Status of Adolescent School Children in Rural North India Indian Pediatr 1999; 36: 810-815.

22. Malhotra A and Jain PS. Diet quality and nutritional status of rural adolescent girl beneficiaries of ICDS in North India. Asia Pac J Clin Nutr.2007;16 (Suppl 1):8-16.

23. Kumaravel V, Shriram V, Anitharani M, Mahadevan S, Balamurugan AN. Are the current Indian growth charts really representative? Analysis of anthropometric assessment of school children in a South Indian district Year: 2014;18(1):5662 . 